Article type : Original Article

489-2017.R2

Original Article (online only)

\title{
An assessment of an Australasian pathway for the introduction of transanal total mesorectal excision (taTME)
}

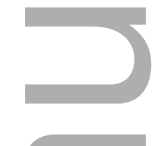

Sarah C. Abbott, MBChB, FRACS, Dr, Division of Colorectal Surgery, Alfred Health

Andrew RL Stevenson, MBBS, FRACS, Associate Professor, Division of Colorectal Surgery, Royal Brisbane Hospital

Stephen W Bell, MBBS, FRACS, Mr, Division of Colorectal Surgery, Alfred Health

David Clark, MBBS, FRACS, Dr, Division of Colorectal Surgery, Royal Brisbane Hospital

Arend Merrie, MBChB, PhD, FRACS, Mr, Division of Colorectal Surgery, Auckland City

Hospital

Julian Hayes, MBChB, FRACS, Mr, Division of Colorectal Surgery, Auckland City Hospital

Shanthan Ganesh, MBBS, FRACS, Mr, Division of Colorectal Surgery, The Queen Elizabeth

Hospital

Alexander G Heriot, Professor, MD, MBA, FRACS, FRCS Division of Cancer Surgery, Peter

MacCallum Cancer Centre, University of Melbourne

Satish K Warrier, MBBS, MS, FRACS, Division of Cancer Surgery, Peter MacCallum Cancer

Centre, University of Melbourne

\section{Corresponding Author}

This is the author manuscript accepted for publication and has undergone full peer review but has not been through the copyediting, typesetting, pagination and proofreading process, which may lead to differences between this version and the Version of Record. Please cite this article as doi: $10.1111 /$ codi. 13964

This article is protected by copyright. All rights reserved 


\section{Satish K Warrier}

Peter MacCallum Cancer Centre, 305 Grattan St, Melbourne VIC 3000, Australia

$+61488054238$

$+61385597379$

satish96101@yahoo.com

\section{Abstract}

$\underline{\text { Aim }}$

To evaluate the use of a pathway for the introduction of transanal total mesorectal excision (taTME) into Australia and New Zealand.

\section{Method}

A pathway for surgeons with an appropriate level of specialist training and baseline skillset was initiated amongst colorectal surgeons; it includes an intensive course, a series of proctored cases and ongoing contribution to audit. Data were collected for patients who had taTME, for benign and malignant conditions, undertaken by the initial adopters of the technique.

Results

A total of 133 taTME cases were performed following the introduction of a training pathway in March 2015. The indication was rectal cancer in $84 \%$ of cases. There was one techniquespecific visceral injury, which occurred prior to that surgeon completing the pathway. There were no cases of post-operative mortality; morbidity occurred in $27.1 \%$. The distal resection margin was clear in all rectal cancer cases, and the circumferential resection margin was positive in two cases. An intact or nearly intact total mesorectal exicision was obtained in greater than $98 \%$ of cases.

\section{Conclusion}

This study demonstrates the safe and controlled introduction of a new surgical technique in a defined surgeon population with the use of a pathway for training. The authors recommend a similar pathway to facilitate the introduction of taTME to colorectal surgical practice.

\section{What does this paper add to the literature?}

This article is protected by copyright. All rights reserved 
Transanal total mesorectal excision is a new minimally invasive technique offering a different approach to rectal resection. Whilst many authors have acknowledged the need for structured training, there are few recommendations for how to safely introduce this technology. This paper presents a potential training pathway in conjunction with outcome data.

\section{Introduction}

Transanal total mesorectal excision (taTME) has resulted from several key developments in the surgical management of rectal cancer. Heald promoted the concept of total mesorectal excision (TME) in 1983 and demonstrated that the technique could reduce local recurrence to $<10 \%$ [1]. At a similar time, Marks developed the technique of transabdominal-transanal (TATA) operation for cancers involving the distal third of the rectum, with the key benefit being dissection of the distal margin from below, ensuring no tumour involvement at the line of division and elimination of the need for stapler transection within the narrow boney constraints of the pelvis [2]. With the widespread introduction of minimally invasive surgery, and the benefit of previous work by Buess in the development of transanal endoscopic microsurgery (TEM) [3], Sylla and Lacy published the first taTME in a human in 2010 [4]. The development of the transanal minimally invasive surgery (TAMIS) platform [5] was a critical key in allowing the amalgamation of Heald's holy plane and a transanal approach, and resulted in taTME as we know it today.

There has been widespread interest among colorectal surgeons with a resultant rapid adoption of this new surgical technique. It is a complex procedure, with a completely new "bottom-up" viewpoint of pelvic anatomy. Initial case series have highlighted the difficulties encountered, which resulted in adverse events, such as urethral injury [6], a complication rarely encountered in conventional rectal resections. Lessons must be learnt from the past, for example the significant increase in common bile duct injuries with the widespread and unregulated introduction of laparoscopic cholecystectomy [7].

The aim of the current study was to evaluate the use of a pathway for training and accreditation in the introduction of taTME in Australia and New Zealand, as reflected in outcome data.

\section{Method}

\section{Pathway for training}

This article is protected by copyright. All rights reserved 
Figure 1 provides a schematic representation of the components of the pathway.

To be eligible to apply to a course within Australia or New Zealand, surgeons must have fulfilled several criteria. Completion of a specialised post-fellowship training in Colorectal Surgery, such as the Australia and New Zealand Training Board in Colorectal Surgery program, which entails two clinical years at accredited units, is a prerequisite. Furthermore, candidates must have independently undertaken at least 200 laparoscopic colonic resections, 50 laparoscopic rectal resections and 10 - 20 transanal minimally invasive surgery (TAMIS or equivalent) cases. They must also be able to demonstrate a sufficient ongoing case volume to maintain the required skillset.

An intensive two-day course has been developed, in conjunction with industry, with three key components; live case(s), a cadaveric workshop and didactic lectures. Theatre nurse participation is encouraged. The objective of the course is to learn the principles of taTME using a flexible transanal access device. Didactic lectures address indications and contraindications, anatomy, patient selection, pre-operative protocol, operating room set up, step-by-step surgical procedure, anastomotic techniques, and contribution to local and international registries. A central repository for the lectures ensures consistency and also prevents faculty members from becoming overburdened. A live demonstration case is performed by a faculty member, with streaming to a separate room for participants and non-operating faculty. There is the opportunity to visit the operating theatre during the live demonstration case, and informal discussion between participants and non-operating faculty is encouraged. A laparoscopic trainer jig is also present for participants to practice the initial purse-string placement. Finally, there is a cadaveric workshop with a ratio of one faculty member to two participants, and two participants per cadaver.

Following completion of the course, each participant undertakes two proctored cases, although these are not formally assessed. Proctors are those surgeons who have attended early courses overseas and the initial course within Australasia. They are not international faculty. Participants are encouraged to move through the pathway alongside a colleague from their own centre, to provide support and enhance situational awareness when encountering the new "bottom-up" viewpoint of pelvic anatomy.

The course and the proctored cases are supported by industry, with course participants meeting costs of approximately AUD1000 to attend. Proctors do not receive compensation for lost revenue, however their travel costs are met. 
The final component of the pathway is contribution to audit through involvement in local and/or international registries.

\section{Data collection}

Data were collected from 8 surgeons across 12 institutions for benign and malignant conditions. Although not compulsory, some surgeons also chose to contribute to the LOREC registry [8]

\section{Tumour characteristics and staging}

Rectal cancer patients were staged with high resolution pelvic magnetic resonance imaging (MRI) and thoraco-abdominal computed tomography (CT). Endorectal ultrasound (EUS) was used in some institutions as an adjunct to MRI. The definition of rectal cancer location was based on a combination of pre-operative clinical examination (including rigid sigmoidoscopy), colonoscopy and MRI: $\leq 6 \mathrm{~cm}$ from the anal verge, low rectum; $7-10 \mathrm{~cm}$ from the anal verge, mid rectum; $>10 \mathrm{~cm}$ from the anal verge, upper rectum. Local multidisciplinary meetings recommended neoadjuvant and adjuvant treatment as appropriate.

\section{Operative technique}

All patients received pre-operative mechanical bowel preparation. Intravenous antibiotic prophylaxis was delivered prior to surgical incision. Unless contraindicated all patients received postoperative venous thromboprophylaxis.

Individual surgeon choice dictated whether or not the transanal component was performed synchronously to the abdominal component, and the method of abdominal access (laparoscopic or robotic). The equipment for and approach to the transanal component was standardised across all surgeons due to consistent teaching methods across all delivered courses. The GelPOINT ${ }^{\circledR}$ path transanal access platform (Applied Medical, CA, US) was the device of choice in the majority of cases.

\section{Outcomes}

Rectal cancers were staged according to the AJCC TNM classification, with involvement of the circumferential resection margin (CRM) being defined as the presence of tumour cells within $1 \mathrm{~mm}$ from the excised non-peritonealised surface of the rectum, and involvement of the distal resection margin being defined as presence of tumour cells within $1 \mathrm{~mm}$ of the distal margin of the unstretched fresh specimen. The quality of the mesorectum was scored independently by the reporting pathologist as described by Nagtegaal and colleagues [9]. 
Surgeon participants and pathologists were all accredited contributors to the ALaCaRT study. Anastomotic leakage was defined as per the International Study Group of Rectal Cancer [10].

\section{Statistical analysis}

Categorical data are presented as number of cases and percentages. Continuous data are shown as either median with range or mean \pm standard deviation. The reported percentages represent the data available excluding any missing variables unless otherwise stated.

\section{Results}

A total of 159 taTME cases were performed by 8 surgeons across 12 institutions from 17 July 2013 to 1 October 2016. The first course took place in March 2015, however 3 surgeons had attended a course overseas prior to this. In total, 26 cases were performed by 6 surgeons prior to the introduction of the formalised pathway (Table 1), as such 133 cases are presented for analysis. Figure 2 illustrates the uptake of the technique over time.

Patients' characteristics are detailed in Table 2 . The indication for surgery was rectal cancer in 112 cases (84.2\%), whereas 20 patients (15\%) had benign pathology. Benign cases included rectal polyps (4,3\%), inflammatory bowel disease $(12,9 \%)$, and other indications (faecal incontinence, familial adenomatous polyposis, full thickness rectal prolapse). Data regarding indication for surgery was not available for one patient.

Mean combined operating time was 287 minutes (range 100 - 525 minutes). Four cases (3\%) were converted to conventional open surgery. There were two cases of intra-operative rectal perforation but no other taTME specific visceral complications, in particular no urethral injuries. Aside from two patients who did not receive neoadjuvant therapy, all patients with an anastomosis had a diverting loop ileostomy created; this was at the discretion of the operating surgeon.

There were no reported cases of post-operative mortality within 30 days; some form of post-operative morbidity occurred in $27.1 \%$ of patients (Table 3 ). An anastomotic leak was recorded in 6 of 111 patients with an anastomosis (5.4\%). A pelvic collection was recorded in an additional 2 patients without evidence of anastomotic leak. Other significant complications included 4 cases of small bowel obstruction ( 2 of which required return to theatre), one case of postoperative haemorrhage, and two cases of small bowel injury (one 
of which resulted in an enteroperineal fistula). Median length of inpatient hospital stay was 7 days (range 3 - 29 days).

A total of 112 rectal cancer cases were analysed. Table 4 outlines the key pathological outcomes. There were only two cases of a positive CRM (specifically tumour at $0.3 \mathrm{~mm}$ and $0.5 \mathrm{~mm}$ from the excised non-peritonealised surface of the rectum), which equates to $1.9 \%$ of cases when only rectal cancers with CRM results are analysed (108 cases). There were no cases of a positive distal resection margin in the 108 cases which reported on this outcome. When those without TME grading results were excluded, an intact or nearly intact TME specimen was obtained in $98.2 \%$ of cases (107 of 109 cases). Pathological complete response was reported in 13 specimens (which equates to $22 \%$ of those patients who received neoadjuvant treatment).

For those cases performed prior to the introduction of the formalised pathway, a greater proportion had a benign indication (rectal cancer $n=17,65 \%$; benign $n=7,27 \%$; unknown $n$ $=2,8 \%$ ). Mean operating time was similar (271 minutes, range $120-521$ minutes) and there were no conversions. There were two significant intra-operative complications; one avulsion of the marginal vessel upon transanal delivery of the conduit, and one urethral injury. These events were recognised and addressed appropriately intra-operatively. There were no reported cases of post-operative mortality; some form of post-operative morbidity occurred in $19 \%$. Of the 17 rectal cancers, there was one case of a positive CRM and no cases of a positive distal resection margin. An intact or nearly intact TME specimen was obtained in all cases.

\section{Discussion and conclusions}

The results of this study demonstrate the safe and controlled introduction of a new surgical technique in a constrained surgeon population with the use of a pathway for training. Postoperative morbidity was comparable to the best published data, with $27.1 \%$ of patients experiencing some form of morbidity. Anastomotic leak rate was very low at $5.4 \%$. The only technique-specific visceral injury (one urethral injury) was sustained prior to the introduction of the training pathway. Length of stay data were satisfactory.

Histopathological results are comparable to the best published data, with greater than $98 \%$ of specimens being a complete or nearly complete TME, and a CRM positivity rate of $<2 \%$. Lymph node harvest was also satisfactory with on average 17 lymph nodes analysed per 
resection specimen. In the absence of long-term follow-up data, these outcomes may be taken as surrogate endpoints conferring oncological safety of the technique.

The largest multicentre series of taTME has recently been published, encompassing 66 registered units across 23 countries [11]. There were 720 consecutive cases, of which the vast majority were performed for rectal cancer. The authors documented an abdominal conversion rate of $6.3 \%$ and a perineal conversion rate of $2.8 \%$. Morbidity occurred in 32.6\%. An intact TME specimen was obtained in $85 \%$, with risk factors for a poor quality TME on multivariate analysis being MRI CRM positivity, tumour within $2 \mathrm{~cm}$ of the anorectal junction, and laparoscopic transabdominal posterior dissection to within $4 \mathrm{~cm}$ or less of the anal verge.

A large single centre two-surgeon series was published by Lacy and included 140 patients [12]. There were no conversions nor intra-operative complications. A complete TME was obtained in $97.1 \%$, and a nearly complete TME was obtained in $2.1 \%$. There were no cases of mortality; minor morbidity occurred in $24.2 \%$ and major morbidity occurred in $10 \%$. Local recurrence occurred in $2.3 \%$, with a mean length of follow-up of 15 months. This series demonstrates the excellent results achieved by one of the taTME pioneers, but is perhaps not reflective of results which could be expected to be achieved upon initial introduction of the technique

There have been at least three systematic reviews published to date; all of which have reported complete TME rates in excess of $85 \%$ and CRM positivity rates of $2-11.8 \%$ [13-15]. Morbidity ranged from 22 to 35\%, with a few instances of urethral injury. Many of the included case series encompassed surgeons at the early point of their learning curve; despite this, the reported outcomes are very encouraging.

There is a paucity of prospective data comparing taTME to current accepted practice. The COLOR III trial, comparing taTME to laparoscopic TME, is presently recruiting and will significantly add to the current body of evidence [16].

Whilst many authors have acknowledged the need for structured training, standardised technique, and careful recording of specimen quality and patient morbidity; there is little evidence regarding the length and steepness of the learning curve and recommendations for how to safely introduce this technology.

Australia and New Zealand represent a unique geographical situation with a widelydispersed patient population and centralisation of specialised care. Colorectal surgery is 
largely delivered by a small group of surgeons, with Australia and New Zealand Training Board in Colorectal Surgery (ANZTBCRS) or equivalent post-fellowship training ensuring a high skillset level. The pathway for training detailed in the article was delivered locally, by local faculty, complemented by a variety of international visitors, and supported by industry. A vital component of the pathway is proctorship, further ensuring the safe introduction of the technique and strengthening of collegial relationships. It should be noted that the only technique specific visceral injury was sustained prior to the introduction of the pathway.

The UK National Institute for Health and Care Excellence (NICE) guidelines recommend that "taTME should only be done by surgeons who are experienced in laparoscopic and transanal rectal resection and who have had specific training in this procedure" [17]. The guidelines also encourage surgeons to enter patients onto the international registry.

A recent international workshop with expert surgeons took the initial steps toward developing a training curriculum for taTME [18]. Prior to the workshop an online survey was conducted in the UK; although respondent experience with taTME was minimal (only $14 \%$ had performed the operation), the majority acknowledged the need for a minimum skillset level prior to learning the technique and for a certain number of cases per unit per year to maintain competence. Components of a training curriculum were also explored; with technical skills training and clinical mentorship in particular being identified as particularly important. A global assessment score (GAS) form was developed, agreed upon and tested during a cadaveric case at the workshop to cover the salient points of the operation and to assist in training. Although this tool is yet to be clinically validated, it may prove to be useful to objectively assess the various essential steps, monitor progression and promote reflective learning.

A German group presented a 2-day training course for taTME which encompassed supervised simulator training, cadaver workstations and observation of live surgery sessions [19]. This proposed course was not presented in conjunction with any outcome data. An American group presented the training pathway undertaken by one surgeon and the surgical team prior to their first taTME [20]. Penna and colleagues presented the transatlantic training experience following six cadaveric workshops, and demonstrated a complete or near complete TME in $81 \%$ of cadaveric specimens with improvements noted between the first and second procedure performed [21]. 
Aside from these articles there is no evidence to support any particular format of training pathway, nor the impact of any such pathway upon the clinical introduction of this technique, and in particular, patient morbidity and histopathological results.

A number of limitations exist to this paper; namely moderate patient numbers and a small number of highly selected surgeons. There is no formal control group, however the cases performed prior to the introduction of the pathway may give some indication of possible outcomes without specific training. That said, this group is very small and as such may not accurately reflect outcomes.

This paper presents a pathway for training for taTME. With the controlled introduction of a new technique in an appropriately trained group of surgeons with a pre-existing high skillset level, excellent outcomes were obtained. The authors recommend a similar pathway, including all the critical components (in particular didactic sessions, attendance at real time surgery, cadaveric dissection and ideally proctoring of early cases), to facilitate the safe introduction of taTME to colorectal surgical practice.

\section{Acknowledgements}

The authors wish to acknowledge the support of Applied Medical ${ }^{\mathrm{TM}}$ in the administration of the course and proctored cases.

\section{References}

1. Heald RJ, Husband EM, Ryall RD. The mesorectum in rectal cancer surgery: the clue to pelvic recurrence? Br J Surg 1982;69(10):613-616.

2. Marks G, Mohiuddin M, Rakinic J. New hope and promise for sphincter preservation in the management of cancer of the rectum. Semin Oncol 1991;18(4):388-398.

3. Buess G, Theiss R, Günther M, Hutterer F, Pichlmaier H. Endoscopic surgery in the rectum. Endoscopy 1985;17(1):31-35.

4. Sylla P, Rattner DW, Delgado S, Lacy AM. NOTES transanal rectal cancer resection using transanal endoscopic microsurgery and laparoscopic assistance. Surg Endosc 2010;24(5):1205-1210.

5. Atallah S, Albert M, Larach S. Transanal minimally invasive surgery: a giant leap forward. Surg Endosc 2010;24(9):2200-2205. 
6. Rouanet $P$, Mourregot $A$, Azar CC, et al. Transanal endoscopic proctectomy: an innovative procedure for difficult resection of rectal tumours in men with narrow pelvis. Dis Colon Rectum 2013;56(4):408-15.

7. Moore MJ, Bennett CL. The Learning curve for laparoscopic cholecystectomy. The Southern Surgeons Club. Am J Surg 1995;170(1):55-59.

8. http://www.lorec.nhs.uk/system/content.asp?pkey=23. Accessed 29 May 2016.

9. Nagtegaal ID, van de Velde CJH, van der Worp E, et al. Macroscopic evaluation of rectal cancer resection specimen: clinical significance of the pathologist in quality control. J Clin Oncol 2002;20(7):1729-1734.

10. Rahbari NN, Weitx J, Hohenberger W, Heald RJ. Definition and grading of anastomotic leakage following anterior resection of the rectum: a proposal by the ISGRC. Surgery 2010;147(3):339-351.

11. Penna $M$, Hompes $R$, Arnold $S$, et al. Transanal total mesorectal excision. International registry results of the first 720 cases. Ann Surg 2017;266(1):111-117.

12. Lacy AM, Tasende MM, Delgado S, et al. Transanal total mesorectal excision for rectal cancer: outcomes after 140 patients. J Am Coll Surg 2015;221(2):415-23.

13. Simillis C, Hompes R, Penna M, Rasheed S, Tekkis PP. A systematic review of transanal total mesorectal excision: is this the future of rectal cancer surgery? Colorectal Dis 2016;18(1):19-36.

14. Arunachalam L, O'Grady H, Hunter IA, Killeen S. A systematic review of outcomes after transanal mesorectal resection for rectal cancer. Dis Colon Rectum 2016;59(4):340-50.

15. Araujo SE, Crawshaw B, Mendes CR. Transanal total mesorectal excision: a systematic review of the experimental and clinical evidence. Tech Coloproctol $2015 ; 19(2): 69-82$.

16. Deijen $\mathrm{CL}$, Velthuis $\mathrm{S}$, Tsai $\mathrm{A}$, et al. COLOR III: a multicentre randomised clinical trial comparing transanal TME versus laparoscopic TME for mid and low rectal cancer. Surg Endosc 2016;30(8):3210-5.

17. Transanal total mesorectal excision of the rectum. National Institute for Health and Care Excellence Interventional procedure guidance, published March 2015. Nice.org.uk/guidance/ipg514 
18. Penna M, Hompes $R$, Mackenzie $H$, Carter F, Francis NK. First international training and assessment consensus workshop on transanal total mesorectal excision (taTME). Tech Coloproctol 2016;20(6):343-52.

19. Aigner F, Biebi M, Fürst A, Jöns $T$, Pratschke J, Kneist W. Training course transanal total mesorectal excision (taTME): concept and establishment of a training course for safe application. Chururg 2017;88(2):147-54.

20. McLemore EC, Harnsberger CR, Broderick RC. Transanal total mesorectal excision (taTME) for rectal cancer: a training pathway. Surg Endosc 2016;30(9):4130-5.

21. Penna M, Whiteford M, Hompes R, Sylla P. Developing and assessing a cadaveric training model for transanal total mesorectal excision: initial experience in the UK and USA. Colorectal Dis 2017;19(5):476-484.

Table 1. Surgeon case volume

\begin{tabular}{|l|l|l|l|}
\hline Surgeon & $\begin{array}{l}\text { Case(s) prior to } \\
\text { course }\end{array}$ & Case(s) after course & Total cases \\
\hline A & 8 & 35 & 43 \\
\hline B & 1 & 21 & 22 \\
\hline C & 1 & 10 & 11 \\
\hline D & 6 & 19 & 25 \\
\hline E & 0 & 20 & 20 \\
\hline F & 1 & 18 & 19 \\
\hline G & 9 & 7 & 16 \\
\hline H & 0 & 3 & 3 \\
\hline
\end{tabular}

Table 2. Patient demographics

\begin{tabular}{|c|c|}
\hline Patient characteristic & \\
\hline Sex, $n(\%)$ & \\
\hline Males & $87(65.4 \%)$ \\
\hline
\end{tabular}




\begin{tabular}{|l|c|}
\hline \multicolumn{1}{|c|}{ Females } & $46(34.6 \%)$ \\
\hline Age in years, mean \pm SD (range) & $61.7 \pm 15.1(14-88)$ \\
\hline ASA score, median (range) & $2(1-3)$ \\
\hline BMl in $\mathrm{kg} / \mathrm{m}^{2}$, mean \pm SD (range) & $27.0 \pm 4.8(17-41)$ \\
\hline $\begin{array}{l}\text { ASA indicates American Society of Anesthesiologists; BMl, body mass index; } \\
\text { SD, standard deviation }\end{array}$ \\
\hline
\end{tabular}

Table 3. Complications

\begin{tabular}{|l|l|}
\hline Clavien-Dindo Complication & \\
\hline I & 4 \\
\hline II & 22 \\
\hline IIla & 3 \\
\hline IIlb & 9 \\
\hline Iva & 2 \\
\hline IVb & 1 \\
\hline V & 0 \\
\hline Not recorded & 1 \\
\hline
\end{tabular}

Table 4. Rectal cancer data

\begin{tabular}{|c|l|}
\hline Histopathological Data & \\
\hline Total number of cancer cases & 112 \\
\hline Pathological T stage, $n(\%)$ & \\
\hline T0 & $18(16.1 \%)$ \\
\hline T1 & $15(13.4 \%)$ \\
\hline T2 & $39(34.8 \%)$ \\
\hline T3 & $40(35.7 \%)$ \\
\hline
\end{tabular}

This article is protected by copyright. All rights reserved 


\begin{tabular}{|c|l|}
\hline T4 & $0(0 \%)$ \\
\hline Pathological N stage, $n$ (\%) & \\
\hline N0 & $84(75 \%)$ \\
\hline N1 & $24(21.4 \%)$ \\
\hline N2 & $4(3.6 \%)$ \\
\hline Quality of TME specimen, $n$ (\%) & \\
\hline Intact & $105(93.7 \%)$ \\
\hline Minor defects & $2(1.8 \%)$ \\
\hline Major defects & $1(0.9 \%)$ \\
\hline Missing & $4(3.6 \%)$ \\
\hline Number of lymph nodes harvested & \\
\hline Mean \pm SD \\
from the excised non-peritonealised surface of the rectum
\end{tabular}




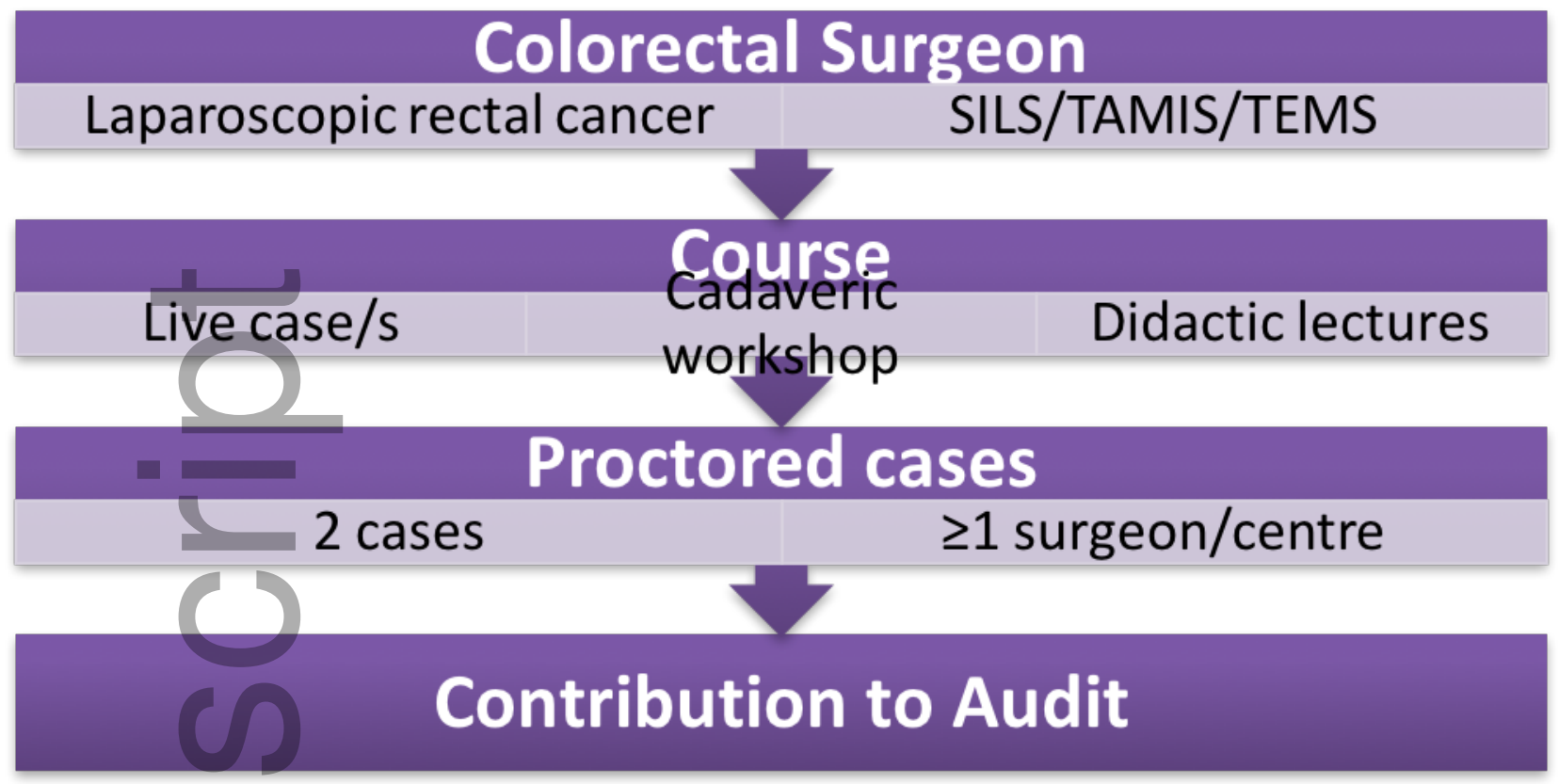

Figure 1. Training pathway

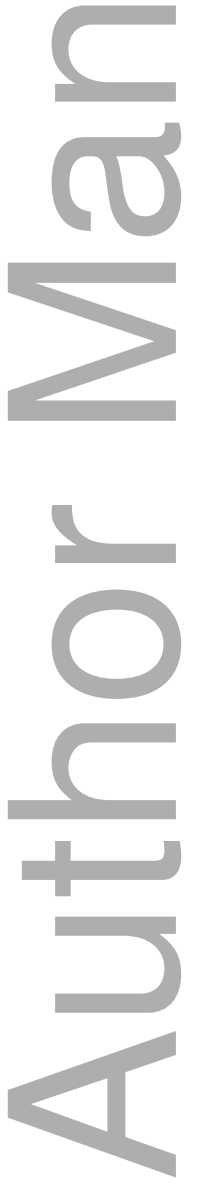


Figure 1. Training pathway

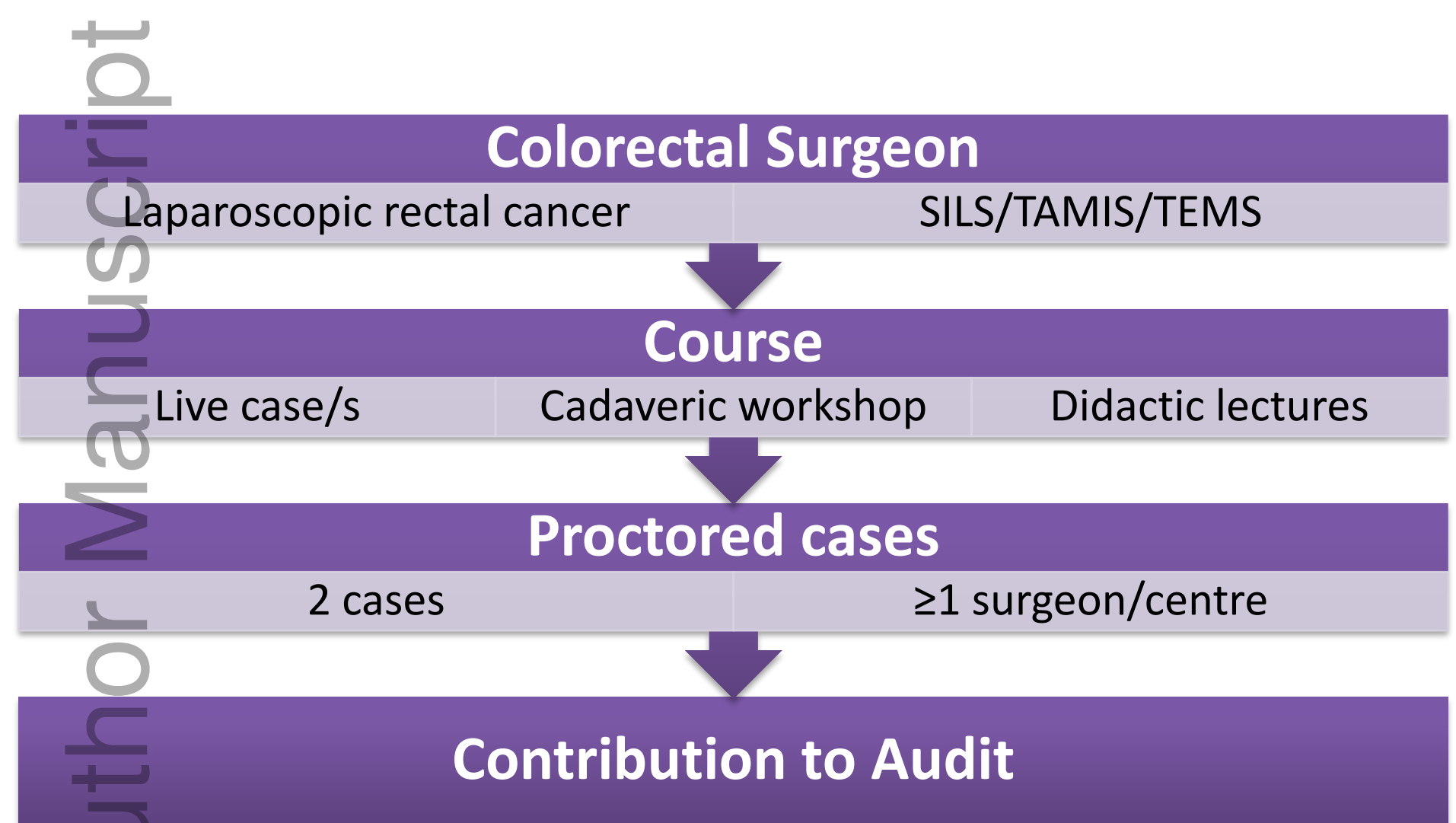




\section{Figure 2. Technique adoption}

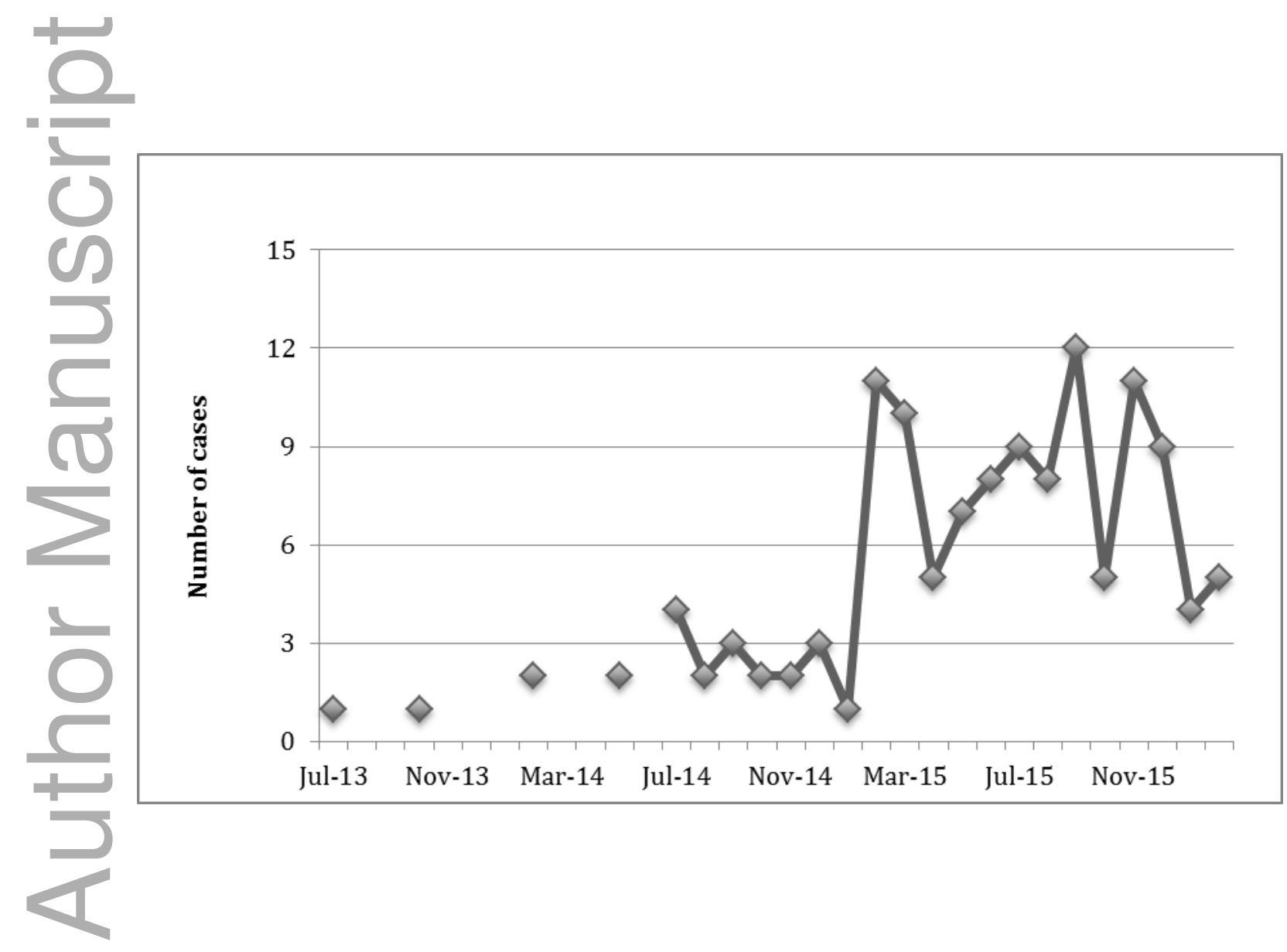

This article is protected by copyright. All rights reserved 


\section{University Library}

\section{- M M N E R VA A gateway to Melbourne's research publications}

Minerva Access is the Institutional Repository of The University of Melbourne

Author/s:

Abbott, SC;Stevenson, ARL;Bell, SW;Clark, D;Merrie, A;Hayes, J;Ganesh, S;Heriot, AG;Warrier, SK

Title:

An assessment of an Australasian pathway for the introduction of transanal total mesorectal excision (taTME)

Date:

2018-01-01

Citation:

Abbott, S. C., Stevenson, A. R. L., Bell, S. W., Clark, D., Merrie, A., Hayes, J., Ganesh, S., Heriot, A. G. \& Warrier, S. K. (2018). An assessment of an Australasian pathway for the introduction of transanal total mesorectal excision (taTME). COLORECTAL DISEASE, 20 (1), pp.O1-O6. https://doi.org/10.1111/codi.13964.

Persistent Link:

http://hdl.handle.net/11343/283438 